\title{
Obtaining 3+ GPA: Students' Learning Perspectives
}

\author{
Pashmina Nisar Pathan ${ }^{1, *}$, Dhani Bux Shah ${ }^{2}$, Nabeel Nisar ${ }^{3}$, Zarina Mustafa ${ }^{1}$ \\ ${ }^{1}$ School of Educational Studies, Universiti Sains Malaysia, Malaysia \\ ${ }^{2}$ Department of Education, Sukkur IBA University, Pakistan \\ ${ }^{3}$ Department of Management Sciences, Sukkur IBA University, Pakistan
}

Received April 6, 2020; Revised May 16, 2020; Accepted June 4, 2020

Copyright (C2020 by authors, all rights reserved. Authors agree that this article remains permanently open access under the terms of the Creative Commons Attribution License 4.0 International License

\begin{abstract}
The present study aims to get an insight into the learning perspectives of students who obtain 3+ GPA at the Business department of a Public Sector University in Pakistan. This study includes 4 undergraduate business students from $8^{\text {th }}$ semester ( 2 males and 2 females) who maintained $3+$ GPA till $7^{\text {th }}$ semester. A qualitative case study approach was selected. The data was collected through semi-structured interviews i.e. one-to-one and focused group interviews. Open-coding strategy was used to analyze data and data was reported thematically. Findings of this study reveal that students perceive learning as practicality approach. Students perceive that learning is whatever they perform in perspective of physical condition and their learning occurs when they are provided with any situation in real context. Finding also shows the harmful factors which hinder students' learning and also suggestions to address those factors. This study has a number of implications for students, teachers and university policy makers. The study provides some recommendations that could be taken into account by university management, policy makers and teachers and in order to set up and deliver effective learning opportunities for students by recognizing different ways of learning, which would bring benefits to students. This study is a first attempt to explore the learning perspectives of students in a business department of a public sector university in Pakistan and it will contribute to low achievers to get higher GPA by applying the results.
\end{abstract}

Keywords 3+ GPA, Business Department, Learning Perspectives, Learning Practices, Students' Performance

\section{Introduction}

Perspective is a method of seeing something. It is a particular way of thinking about something that is influenced by one's experiences of beliefs. It is a Latin word which means "view" or "perceive" [1]. In universities, students' population is becoming diverse. They are coming from diverse background having different culture, orientation to learning, ethnicities, religion, prior experience and academic capabilities [2]. Therefore, university students held different perspectives about their learning as their perspectives are influenced by their prior beliefs and experiences. The grade point average "GPA" is a system of evaluating students' performance. Study of research shows that those students who are engaged in higher order leaning obtain high GPA [2].

Perception of students is obtained by the way through which they approach their learning. Since 1970s researchers have given focus on the individual difference and the ways through which students approach their studies and learning tasks [3]. Research has indicated three concepts through which a students' approach their learning and to achieve their learning goal. First one is deep learning; it states to understand ideas by connecting with each other and using comprehensive evidence. Second is surface learning that suggests memorizing and reproducing ideas. Third is approach that is strategic approach, it relates to students' tactics to engage in learning and manage the time, it is more related approach to studying [3]. In university experience, there are many aspects that affect students' perception about learning as well as their performance [4]. It is supported by the literature that contextual factors also affect students' goal choice and learning activities. However, study of research shows that the students' achievement depends on the interaction of contextual and individual factors [5].

Study of Alfan, and Othman reveals that the factors including gender, age and engagement in extracurricular activities have no effect on students' performance. Moreover, the GPA is found to be positively and strongly related to students' performance [6]. Students who obtain good GPA have positive attitude towards study and those students also perform well in classroom activities. One of the findings of the research indicated that the academic 
achievement of students is associated to the attitude of students towards the subject, interest, time, teachers' influence and perception of parental support, and socio-economic status.

The GPA system is prevailing in most of the universities of Pakistan. Students who obtain higher GPA are considered as the source of workforce for the country's economy [7]. There are many factors that affect students' performance. This study mainly focuses on knowing the potential factors which influence students' performance. This study will explore students' learning perspectives about getting good grades and scoring higher GPA in a university. As constructivist approach suggests that every student gets different experience so their perspectives regarding learning are also different [8]. There is a gap found in the literature because there are very less number of research studies that have been conducted to understand the importance of grades and perceptions of the students where their thoughts are discovered behind obtaining the good grades and CGPA (Cumulative Grade Point Average) in the university [9].

The purpose of this study is to get insight about the learning perspectives of students who obtain 3+ GPA at the business department of a public university in Sindh, Pakistan. A qualitative case study approach has been used, with semi-structured survey interview guides for collecting data. With this purpose, the study is directed with research questions including:

1. What are the learning perspectives of students who obtain 3+ GPA?

2. What are their perspectives about $3+\mathrm{GPA}$ ?

3. What are the learning practices of students who obtain 3+ GPA?

4. What are the facilitating factors that affect students' performance?

5. What are the hindering factors that affect student's performance?

6. What are the suggestions to address the hindering factors that affect students' performance?

\section{Literature Review}

In this section a brief review of literature is given. This section is divided into 6 parts including Students' perspectives, Learning and learning perspectives, 3+ GPA and importance of obtaining 3+ GPA, Challenges in obtaining 3+ GPA, Importance of obtaining 3+ GPA in business schools and Importance of obtaining $3+$ GPA in business schools of Pakistan.

\subsection{Students' Perspectives}

Students' perspectives and experiences provide an in-depth information about their motivation in getting 3+ GPA apparently. Han and Ellis suggest that students' learning perspectives are influenced by different factors including students' conception of learning and their approach to learning. The perspectives of students including their prior knowledge, experience and how they approach their learning tend to have direct impact on their success and failure. Students' motivating perspective are the main cause behind their success and failure in any task [10].

Han and Ellis explain that collaboration and discussion are the two main tools which help students to communicate, argue, negotiate and reflect upon existing beliefs. Through these tools students can also communicate their perspectives about learning with each other and construct their knowledge. Han and Ellis identify that beliefs, perspectives and prior experience play important role in understanding how students approach and process information.

\subsection{Learning and Leaning Perspectives}

Learning occurs by observing the environment and enacting social roles in community [11]. When a person interacts and plays different roles in community, the learning starts, Reference [12] shares that according to social constructivist approach, learning is constructed in human mind and this construction occurs when a person interacts with surroundings through discussion, conversion and negotiation process. They further added that students can learn knowledge, skills and values through purposeful engagement with culture [12].

Learning is no more acquiring knowledge once for all rather it is a lifelong education which can produce a complete person who can learn to evolve with changing circumstances, adopt new changes and deal with challenges [13]. Learning occurs through meaning making, it involves learner in a process of sharing ideas and perspectives with each other in a learning community [12]. Previous research identifies that leaners' learning is shaped along with the passage of time. Kuo, Belland and Kuo. explain that change in surrounding occurs over the time, with the new changes learner learns new things as well as gives shape to the previous learning.

It is also acknowledged that students' learning perspectives and the way they approach learning are significant factors of the excellence of their learning products [14]. Students are the agents of their learning, therefore it is important for a teacher to develop the understanding of the learning perspectives of students in order to enhance the teaching style [15]. For understanding the learning perspectives of students, teachers should give their focus to students and improve his/her teaching style accordingly.

\subsection{3+ GPA and Importance of Obtaining $3+$ GPA}

3 + grade point average is well-known ranking system of 
students’ performance in many universities. Maintaining 3 + GPA in university means having 3 grade points and having grade $B$ or above then $B$ [16]. The total percentage of 3 + GPA is ranked differently in different universities. The grade point average is also known as class rank. Lang further added that class rank is becoming gradually important measure.

It is recognized that the retention of $3+$ GPA has many potential factors behind it [17]. In four years of degree students' prior academic achievement also help in getting higher grades in university. Students' achievement is influence by their activities inside and outside the classroom, which includes curricular activities, academic activities and social activities. A proper utilization of such resources also impacts on students' grades [17].

Grades are one of the silent tools in classroom settings which indicate the performance feedback of student. Grades have given one of the essentials positions in our community [9]. In university setting, grades are the performance feedback of students which they receive in return of hard work [9]. Grades also carry importance in students' life, and also help students in career decisions. Grades also keep students motivated toward achieving their goal [9].

\subsection{Challenges in Obtaining $3+$ GPA}

In first year, college students face an extensive transition from high school to college [18]. These are the basic years in which students experience number of challenges in obtaining 3 + GPA. Furthermore, study shows that in these early years some students feel out of control, which makes them perceive college as a low control environment considered by academic struggle. Such students take college life for granted and after completing first year they start facing number of challenges in obtaining good grades, ultimately it leads them towards failure [18]. On the other hand, some students feel in control, which leads them better awareness of responsibility, less negative effect and increased motivation.

The literature review shows that students face a number of challenges in obtaining good grades and in a result, they drop out from university. Some challenges include low academic achievement, absenteeism, teacher-assigned grades, grade retention and family socioeconomic status [19]. According to Wernersbach, Crowley, Bates, and Rosenthal, self-efficacy is one of the factors for avoiding challenges which occurs in achieving a particular task. For achieving any task students should have firm believe in their capability.

\subsection{Importance of Obtaining 3+ GPA at Business Schools}

Waseem and Zarif explore that students intensely base their career choices on their grades rather than their interests and aptitudes. The demand of companies who need skillful graduates is generating interest among the youth to get education in business for the sake of securing their future career. Students in business school mainly focus on their grades, they try to get higher grades for the sake of achieving higher position in future career.

The study of Lang suggests that GPA is getting a great importance in colleges and universities specifically, this is also mentioned that most colleges and universities are relying on the notion of GPA at the time of admission decisions for students and this becomes important to students and their parents to get more GPA because colleges and universities are valuing such grades.

\subsection{Importance of Obtaining 3+ GPA at Business Schools in Pakistan}

Business management schools in Pakistan are comparatively different among other specialized schools such as law, medicine, social work, engineering, education and architecture in terms of the degree of reward from the profession that they serve. Due to such importance, business management in Pakistan is also getting expensive [21]. Generally, Pakistani Business Schools offer four-year honorary degree in Business Education. Ullah, Richardson and Hafeez explain that the Pakistan education focuses on obtaining good grades, and Pakistani education system gives importance to obtaining good GPA in universities.

Student's quality actually leads towards success of universities. According to literature in Pakistani universities, traditionally the concept is that the students should be replicators and reproducers of existing wisdom but now the approaches are in transition that believes in generating new knowledge of the physical world that not only improves student's intelligence but also improves their grades to have a better future [23]. According to Hoodbhoy, the grades and academic achievement for the Pakistani students have become so important in the sense that those who want to go for USA need to be so sharp and very good in their academic records so that if they go, they would have enough capability to survive in the other educational system with new ways.

In business schools, obtaining 3+ GPA has given greater importance because many of the companies in Asia prefer those students who maintain 3+ GPA in university. Findings of literature review show that business school gives importance to GPA from the very first day as for admission they also prefer those students who had good record in grades [16]. Business career is emerging profession in Pakistan and greater number of students are getting admission in business schools. Key findings of literature review show that students in Pakistan are giving more focusing on maintaining their grades as they want to get admission in abroad for further education and for getting that they want to develop their skills and grades to approach that educational system [23]. 
Hence, there is a need of exploring students' learning perspectives who obtain 3+ GPA in business schools. The importance of exploring such perspectives may help those students who struggle in obtaining 3+ GPA. Such findings will help other students to adopt those practices and strategies for getting 3+ GPA in business schools and also help them in building their successful career.

\section{Methodology}

In this section the methodology used in for conducting this study is defined. This section is majorly divided into 5 major sections. It includes research design, Research Sample and Participants, Data Collection, Data Analysis and Validity.

\subsection{Research Design}

The purpose of this study was to understand the learning perspectives of students who obtain 3+ GPA. Keeping in view the core purpose of the study, qualitative case study approach was selected to conduct the study. Qualitative research helps in exploring rich data from real world and also allows participants to speak for themselves [24]. The case study approach is the qualitative analysis where the data of a particular organization with its background is given, this data actually helps to find out the particular problem facing by the organization [25]. This study focused on 4 students, who obtain 3+ GPA in Business Department of a Public University in Sindh, Pakistan. Data was collected through in-depth and focused group interview.

\subsection{Research Sample and Participants}

Business Department of a Public University in Sindh, Pakistan was selected as a research site for this study. Business Department was selected because this is one of the oldest and largest departments in the public-sector university. Aim of this study was to explore the learning perspectives of those students who obtain 3+ GPA as their perspectives helped other students in getting 3+ GPA. Secondly, this department was in the University of one of the researchers, so it was accessible for researchers to collect the data.

Creswell suggests purposive sampling for qualitative research in which researcher selects people who can best help in understanding the research question in detail. So, under the purposive sampling, students of Business Department of Public Sector University were selected research participants. Only those students who obtain 3+ GPA were selected. Students who have maintained their 3+ GPA were selected from 8th semester. With the permission and guidance of head of Business department, 4 students who maintained their 3+ GPA were selected throughout their degree in order to explore their different perspectives about securing and maintaining 3+ GPA in their 4 years' degree.

Out of four students two were male and two were female. They all were studying in the last semester of BBA degree and they all had an experience of 2 months' internship in well-known companies. Three of the research participants were from Sindhi ethnicity, and one was from Pathan ethnicity.

\subsection{Data Collection}

For conducting interviews, semi-structured one-to-one and follow-up interview guides were developed, which were composed of open-ended questions. In semi-structured interview, an interview guide is developed but during interview some follow up questions may be asked, which are not the part of guide, rather they are generated from the answers of participant, sometimes these questions also give new and unexpected direction to the research [26].

For exploring the learning perspectives of students who obtain 3+ GPA, one-to-one in-depth interview as well as focused group interview was used as a source of data collection. Bogdan and Biklen suggest that in qualitative research, researcher uses interview for collecting data which helps in developing the insights of how a participant views some aspects of the world.

Data collection process was followed by two steps. First of all, one-to-one in-depth interviews were conducted from 4 students from the Business Department of a public sector university to explore and understand their learning perspectives. Then, each interview was transcribed, and gapes were identified in two interviews, which needed more explanation, on the basis of those gaps another follow up interview guide was made [28]. In second step, follow-up interview was conducted from all participant to fill those gaps which were found in one-to-one interviews.

\subsection{Data Analysis}

Data was condensed, which was the first step of data analyses. "Data condensation refers to the process of selecting, focusing, simplifying, abstracting or transforming the data that appears in the full corpus of written up field notes and interview transcripts and other empirical material” [29]. Each interview transcript was thoroughly read, and codes were given. Codes are the phrase or label given to the chunks of written transcript [26]. Open coding strategy was used. It is the type of coding in which researcher gives instant codes without following any list of pre-planned code. In this process data was read intensely, while reading the particular codes emerged which demonstrate the experience of participants [26]. Once again, the same process was repeated to see whether new codes are emerged. Then, data was condensed 
by eliminating the repeated codes.

The second step was data display. Miles, Huberman and Saldana described this step "as organized, compressed assembly of information that allowed conclusion drawing and action". In this process, table was constructed, which was based on construction of codes. All chucks of information or quotation of participants from each interview were merged in the same row which contained same codes. In this way coding category was developed.

The third step was drawing and verifying conclusions. In this step conclusions were drawn by constructing themes from coding categories [29]. One theme contains two to three or more coding categories. In this step, data analysis was completed by going through a thematic analysis process [28]. Thematic analysis process consists of themes or broad categories of ideas emerged from data [28]. Resultantly, 3 key themes emerged from my research study include; perspectives for learning facilitates to Get 3+ GPA, getting 3+ GPA- key factors and getting 3+ GPA- key hindering factors.

\subsection{Validity}

Validity is known as the credibility or correctness of research findings or conclusion [30]. Maxwell explained that "Validity in qualitative research was not the result of indifference, but integrity". For qualitative research, a researcher has to be honest while drawing the findings and presenting the real data. In this study, I have in-depth interviews which were taken in two steps, themes were constructed after transcribing each interview. Literature regarding validity in qualitative research showed the threat to this study that had Researcher Biasness. In qualitative study researcher tries to understand the believes and perspectives of participants regarding any particular topic. Due to which sometimes researchers own believes effect the conclusion of study in this way researcher biasness occur [30]. Crewel suggests that for checking the accuracy of data a researcher should at least use two strategies.

For addressing this threat two strategies were used. One of the strategies was an expert review, it is an approach in which supervisor or an expert person who is aware about the research, review the data and research process. In this review an expert provides support and critical feedback for the researcher [31]. Feedback was taken from the supervisor of this research at every chapter of the thesis for at least two times. He used to review and give constructive feedback which was incorporated. This process of review and feedback occurred till the completion of thesis. Another strategy used was respondent validation. In respondent validation, data was shared with research participants from whom data was collected and got feedback from them regarding interpretation. It is strategy in which a researcher shares the data with research participant to check whether the data is misinterpreted or not and identify the biasness and misunderstanding in interpreting the data [30]. Through these two strategies, reliability and the validity of data were verified.

\section{Findings}

A deep process of inductive data analysis of the collected data for this research study led to identify 3 key themes that have predominantly emerged from the data analysis procedures. This section presents a systematic arrangement of findings, supporting each research question and theme. Analytical commentary is also provided for each listed finding. The first two research questions "What are the learning perspectives of students who obtain 3+ GPA?" and "What are their perspectives about 3+GPA" come under the theme Perspectives for learning facilitates to get 3+ GPA. The third and fourth research question "What are the learning practices of students who obtain 3+ GPA?" and "What are the facilitating factors that affect students' performance?” come under the theme key facilitating factors that influence to achieve 3+ GPA. The fifth and sixth research questions "What are the hindering factors that affect student's performance?" and "What are the suggestions to address the hindering factors that affect students' performance?” come under the theme key hindering factors that affect achieving 3+ GPA.

\subsection{What are the Learning Perspectives of Students who Obtain 3+ GPA?}

\section{Perspectives for Learning Facilitates to Get 3+ GPA}

The process of interviewing students for this study helped researcher to discover different perspectives of students, which lead them to get 3+ GPA during their degree. Learning has given the great importance in students' life, and especially those students who get 3+ GPA hold strong and resilient views about learning. Every student gives importance to learning in his/her life, and also carries different ideas about it. Every person has different perspectives about learning, but data reveals that students, who were interviewed for this study described their perspectives about learning with many similarities. One student of Business Department who is in the last semester of BBA, shared her perspectives about learning as, "learning is getting knowledge about something, getting something in practice, getting something in your own action that is what learning is". It reveals that this student perceives learning on 2 levels- getting knowledge and applying it. To this student, learning means getting new knowledge, understanding it clearly, and after understanding applying that knowledge in her daily life.

In the same way it is fascinating to explore another student of BBA, semester 8 of the same Business Department, who was interviewed for the same study shared the similar views about learning. She added:

In my view, learning is that if you are studying something so you should implement that practically, 
right. And in BBA degree according to me till now, till 6th semester we have no learning. What we do was study and give papers, study and give papers. Now in last semester we went to [...] [a private university] and in that we play simulations in real from which we get more experience, we interact with other students, give presentations in front of them then it feels like now some learning occurs. So, if we are talking about learning then in each semester there should be a tour. That whatever you are learning you should practically see that whether it happens in market or not. There should be practical approach.

These findings show an interesting view of this student who perceives learning as practicality approach. This student is found critical and perceives that learning is whatever we perform in perspective of physical condition. As per this student learning occurs when she is provided with any situation in real context. It illustrates that this student is in favor of a practical approach that facilitates students' learning. Findings reveal that when a student applies any learned knowledge in real life context then she sees the different aspects of that learned knowledge, identifies its weaknesses and strengths and explores its different application areas.

In the same context, another student from semester 8 of BBA degree from the Business Department shared his ideas about learning:

From 1st semester to 8th semester whatever I have studied in that which are occurred through activity based that are mostly beneficial and easy to remember and in other things we have to use our mind just to remember that. Through implementation and activity base if anything occurs then that is easily remembered, and it has effect.

The above-mentioned findings identify that to this student practical learning has a lot of benefits. It facilitates students to understand the topic easily. It keeps him away from rote learning of different concepts and helps him to get the conceptual understanding. Findings also reveal that this student preceives practical approach easy one as she is engaged in the activity-based teaching. It also facilitates her to learn different concepts throughout her life.

However, it is important to note that learning itself cannot occur, learning occurs through different sources. It may not be possible for learning to occur without sources. Data reveals that it is important to know the different sources of learning through which it occurs. Another Student from Business Department who is in last semester of BBA degree talks about the sources of learning during his interview. He explained:

Learning occurs through different forms whether its classroom learning then another is learning from peers, then there is self-learning which you mostly do learning through reading different books referent to the library whether it's a digital library of you are learning from social media and other electronic media forms

Findings reveal that this student gets help from different sources of learning. He has identified those different sources. For example, he learns from classroom studying through books, notes and power point presentations given by teachers. He also learns from his peers by having constructive discussions with them. He also does self-learning by reading himself. Findings disclose that social media including YouTube, Facebook, Twitter and Google also facilitates this student in his learning.

Agreeing to these findings, another student from BBA who is studying in 8th semester added an example of learning, "we have learnt business through the source of case studies by solving the models, by solving the prototypes of different companies, by solving the problems of different companies we have learn the business knowledge". It pinpoints that except above discussed sources there are also some other sources through which this student learns. She learnt best when she is provided with different models. She learnt her business knowledge when she is engaged in solving prototypes of different companies because during solving prototypes, she is engaged in practical learning and solves the given situation.

\subsection{What are Their Perspectives about $3+$ GPA?}

\section{Perspectives for Learning Facilitates to Get 3+ GPA}

In any university GPA is given importance very much. Maintaining 3+ GPA has become important for university students. Data reveals that students who were interviewed for this study set their mind that they have to get 3+ GPA throughout their degree programme. While identifying the reasons one of the BBA students, who was interviewed for this study explained:

3+ GPA is first of all it was not much concerned that I should get 3+ GPA or initially as we join university. So, later we came to know that different organizations have set their level that applying for GTP or OG1, OG2 you should have minimum $3+$ so that fixed in the mind of student that we have to get $3[\ldots]$ otherwise they are going to suffer in future after the graduation.

Findings show that in marketplace 3 GPA has given a lot of importance. In the beginning of the semester this student was also unaware about the importance of 3+ GPA, so he was also not giving much importance to get higher GPA. However, as he came to know about its value and the demand of companies because many companies have set a policy of only offering jobs to those students who obtain 3 GPA so, this student also set his mind that 3+ GPA is necessary for securing the future and he started maintaining it during his BBA degree programme.

A strong link of 3+GPA to job market is emphatically explained by another BBA semester 8 student. She shared:

A lot everywhere in market they ask for 3 GPA, only those can apply who have $3+$ or 3 GPA. So, I have set 
that focus in my mind not to take less than 3 GPA instead it can be above 3 GPA, so I do hard work on that basis.

Above findings explicitly reveal that this student has set a focus towards getting 3+ GPA because as per her it would be easy to get job if she maintains $3+$ GPA. Focus of maintaining 3+GPA has positively motivated this student to do hardworking in order to secure and maintain 3+ GPA throughout her degree programme.

\subsection{What are the Facilitating Factors that Affect Students' Performance?}

Key facilitating factors that influence to achieve 3+ GPA

A popular explanation of anything comes with its influences. This theme of the study discusses the details of those major factors that influence students (who were interviewed for this study) to get 3+ GPA at the Business Department of a public sector university of Sindh, Pakistan. Data highlights that these students perceive that the grading policy of their university helps them to get stick with their goal. In this regard, one of the student of BBA, who is in her last semester at the Business Department shares about the benefits of grading policy, "like it [grading policy] motivate students and ask them to study otherwise like there is a trade, trade is that they will drop so for saving their years they do work hard to get GPA". It displays that according to this student the grading policy of his university motivates her to work hard and get good grades. She feels that if she will not work hard then there is a chance to get dropped out from the degree. Thus, the grading policy of the university proves to be beneficial for students in terms of making them responsible to stick with their goal, do hard work and maintain $3+\mathrm{GPA}$ to continue the successful pursuance of their degree.

On the other hand, it is interesting to explore the influence of getting 3+ GPA in rapport building at the university. Data from the interview of students reveals that those students who have higher GPA than others are given more importance at the university. Exploring this influence, one of the students of Business Department who is in the last semester of his BBA shared in the interview:

They more focus on such students because on the basis of GPA they judge that this student has more learning, whatever question they ask we respond them through this we also get to know that in mid-term and 2nd mid-term how much marks we will get [...] it also help[s] out in our sessional as teacher is based on [teacher focus on] [...] direct performance which is classroom participations and secondly quizzes so they combine both and evaluate overall. Mostly I have seen that who has good GPA that person also get more sessional as compare to those who has low GPA.

The above-mentioned finding reveals the observation of this students about getting marks from teachers. According to this student, teachers give more marks to students who participate more in classroom activities and get good marks in quizzes. It also shows that 3+ GPA helps this student having 3+GPA to maintain her image in teachers' eye and get good sessional marks.

Learning environment is found to have greater impact on learning of students. Data from the interviews reveals that student shows positive result when they are provided with their preferred learning environment. While discussing about the learning environment, one of the students of Business Department who is in the last semester of BBA shared his views:

There should be flexible chairs and you have learning environment where all students should be participant like there should be two-way communication not like traditional classroom where teacher comes teaches and go, it should be interactive. And of course, besides this infrastructure [...] in June July classes are on and AC is not on so of course it will irritate you means your focus will not be on teacher so these AC, flexible chairs infrastructure matters.

The above findings reveal that this student prefers interactive learning environment. He does not like that environment where only teacher is active, and students are just passively listening. He encourages environment in which he is also given chances to interact with classmates, shares his ideas and listen others' ideas, so as per him, this type of learning influences him to get good grades, and thus helps him to maintain 3+GPA. Furthermore, it is important to note that for this student the air-conditioned (AC) classrooms are considered as conducive learning environment because his university is located in one of the hottest regions of Sindh province. He added that flexible chairs and other infrastructure of classroom are also important in learning.

Supporting his ideas, another student of BBA degree, who is also in last semester shared during the interview about the importance of environment in library which facilitates her learning. She added:

Silent environment like not in discussion room because in discussion room we talk more so it's better we study, outside everyone does their study silently and if anyone has any question so they ask from other silently, sit in group but silent.

According to this student, in library everyone should do their work silently. It is interesting to note that this student is not in favor of discussion room provided by library. She shares that in discussion room she and her group talk more, make noise, discuss irrelevant things but she prefers to study outside the discussion room in groups where they can discuss to the point, and ask questions from each other without making an unnecessary noise. The silent and formal learning environment of library helps her to avoid informal discussions in group, which occur in discussion rooms of library.

Besides learning environment, extra-curricular activities 
also play vital role in learning of students. Data from the collected interviews of students reveals that students give their focus to extra-curricular activities as it also helps them in their studies. One student of Business Department who is in the last semester of BBA degree shared her experiences of extra-curricular activities:

I took part in one training, I was the organizer of that training but in that training being an organizer I learn a lot of things, that was the training about how to start and run your business so it was business related things I would share my experience that till that I did not studied any marketing subject $[\ldots]$ and one important topic in marketing is 4Ps...it is very good and important topic of marketing. I get to know these things through that training, I did not study any subject before. Because application of 4Ps were occurring there [...] it helped me a lot because $[\ldots]$ after a month I got the subject of principles of marketing which is the first subject of marketing. So, I already had much information regarding that. So, this was the activity which help me out in academics.

The above mention findings show the positive impact of extra-curricular activities on this student's learning. It is motivating to explore that extra-curricular activities helpthis student in learning her content knowledge. This student shares that she took part in one of the trainings as organizer that training was about how to start and run your business. This student learnt one of the most important topics of marketing, which is $4 \mathrm{P}$ in a training programme. This training also helped her in a subject 'principles of marketing', which she took after a month of the training programme because she had already learnt much information regarding that subject from the training programme. It is key to note here that the engagement in the extra-curricular activity of engagement in a training has proved helpful for the academic studies of this student.

\subsection{What are the Learning Practices of Students Who Obtain 3+ GPA?}

Key facilitating factors that influence to achieve 3+ GPA

For maintaining 3+ GPA, and getting focus and importance at the university, students have to adopt some practices to get 3+GPA. Data from the students whom I have interviewed for this study highlights some essential practices, adopted by students to get 3+ GPA. One of the BBA semester 8 students of Business Department, who was interviewed for this study said:

Consistency towards studies, consistency towards getting learn more and more things, more and more things in sense related to education [...] I am not like that [...] I should know about manufacturing industries, I should know about cars, Rolex watches [...] about all these. I have focus [of business studies] that what I have to study I should have that knowledge in that area as I have good grip on that.

Above findings reveal that the essential practice of this student for getting 3+ GPA is to remain consistent. For example, she remains consistent towards her studies and tries to learn more and more things related to education. She also highlights that knowing all things does not mean that she should have knowledge of all irrelevant things which are not connected to goal. Moreover, she added that she knows her focus so she gets the knowledge related to her focus as she can have good grasp on her focused area that is related to her business studies including courses, projects, and assignments related to different courses.

Along with essential practice, students also share about some sources except books. Data from the students whom I interviewed reveals that nowadays for study students in university rely more on other resources except only books. In this regard another student of BBA semester 8 revealed in her interview:

[...] Rather than books I personally go for google on google different websites are available like for solutions we use Chegg, we use the website of course hero, we use student corners, we use digital library, we use research papers of different journals, likewise different sites we don't use google scholar much due to authenticity problem so we mostly [...] went for Emerald [...] use the articles of Emerald as instructed by our teacher. We find the articles of Emerald more authentic [...] And yes being marketers we mostly go for the information in magazines [...] we go for Pro Pakistani, we go for Dawn [...] Economist is a good magazine we use that, we use Times of India $[\ldots]$ now mostly we work on net.

Findings show that she goes for a Google search rather than using only books. She uses Chegg, which is site on Google for solutions. She also uses course hero, student corner and digital library provided by her university. She also uses research papers from Emerald. According to her Google, scholar has some authenticity issues so Emerald is more authentic for her. Moreover, she added that as she is marketer, so she also prefers some magazines for collecting information. Some of the magazines she shares are Pro Pakistani, Economist, Dawn and times of India. The above findings highlight that teachers also tells the authentic websites to students and instruct them how to use them.

Simultaneously, another student of semester 8 from the Business Department, who was interviewed for this study shared about the uses of internet. He added that "yes online mostly on YouTube whatever concept I don't understand [...] search that in YouTube so on YouTube mostly a person teaches through slide or through pointing out by lecture wise [...] mostly I took that and almost every subject is available there". Findings show that this student mostly use YouTube for understanding any concept, and he is found happy that he can find most of the concepts related to different subjects on YouTube. He searches out any difficult concept on YouTube and watch that to get an understanding about that 
concept.

\subsection{What are the Hindering Factors that Affect Student'S Performance?}

Key hindering factors that affect achieving 3+ GPA

There are always two sides of coin, and there is always some negativity with positivity so in these findings there are also some hindering factors to affect 3+ GPA along with it influences. Data from the students who were interviewed reveals that students also face some hindering factors in maintaining their GPA, but it also shows that students have learnt some ways to address those hindering factors. Discussing about the hindering factors, students of Business Department who were interviewed for this study talked about the reason of students who get low GPA. One of the students shared:

They are more involve[d] in extra-curricular activities who did not get 3 GPA and they are also not included in hard work because mostly they have a perception in their mind that we will study at the end time and clear the subject $[\ldots]$ So, in the beginning they have a perception that this is a course and we will memorize this at end time [...] Yes only one day you are studying day and night that is not included in hard work because hard work is not about one-day hard work in continuously struggle.

One may see a bit contradiction in this finding and in the above-mentioned finding, where one student has reported that extra-curricular activities help to get 3+ GPA however, it is important to note that this student is mentioning about the loss of studies if a student is involved excessively in the extra-curricular activities. For example, these findings highlight that those students who get low GPA are more or excessively involved in extra-curricular activities than their studies. According to this student, they have already set their mind that they will study one night before the exam and get the passing marks. However, to this student, studying for only one day does not consider as hard work as hard work is continuous. According to her more involvement in extra-curricular activities and taking short cuts for exams, these are the main reasons of getting low GPA.

Moreover, from the data it is found that except these things there are some other factors, which also affect the learning of students. In this study, a student of Business Department from BBA semester 8 shared some other external factors:

Family, family events sometimes they come in exams, before one week of exams family events occurs [...] marriages, any funerals these type of events except that of course friends, friend circle, they come in exams with some program or party [...] mobile, social media it has been an addiction to use a Facebook. We study for 5 minutes and use cellphone for half hour $[\ldots]$ So $[\ldots]$ these all things somehow hinder that in your academic.

Findings reveal that there are three hindering factors that affect the studies as well as GPA of this student - family, friends, and social media. Sudden events in family such as funeral and marriages as they occur in the days of examinations, and they are also important for him to attend. Further, he explains that his friends also become the reason of the hindrances in his studies. Suddenly, his friends come with some program or party during examinations and ask him to join. He also talks about the social media as one of the biggest external factors that hider his learning, which has become the obsession nowadays. He shared that studying for 5 minutes and using cellphone for half hour have become addiction to him.

\subsection{What are the Suggestions to Address the Hindering Factors that Affect Students' Performance?}

Key hindering factors that affect achieving 3+ GPA

Along with hindrances there are always different ways to avoid such hindrances. Data collected from the students who were interviewed discloses that students also tried to manage the hindrance to deviate its effect on their learning. Student from the Business Department, who is in the last semester of BBA degree programme shared in his interview about unavoidable family events, he added:

Sometimes some things are unavoidable you cannot do that. Such event like funeral or marriage ceremony of close relative so anyhow you have to participate in that. So, I try to complete my academic activities before that event by doing anything and by putting more efforts because I have to participate in this thing anyhow.

This student shares that some sudden events of family are unavoidable. He added that funeral and marriages ceremonies of close relatives are important in which he has to participate at any cost. Above findings portray that for addressing these hindering factors this student tries to complete his assignment well before the deadlines. This helps him to manage his studies and planned and unplanned family events effectively.

Simultaneously, discussing about the managing time in extra-curricular activities one of the students of Business Department who studies in BBA in last semester shared her routine:

If you are active in classes so out of class except those 4 hours you can give time to these [extra-curricular] activities [...] if you are dull in 2 to 4 hours of class [...]and after the class, you are going to extra-curricular activities so what happen through this your academic life get disturb right. If you are listening attentively 4 hours in class, participate, note down each thing, make your diary then in exams [...] you will face no difficulty. Then after the class the time which you have, give that to extra-curricular activities. 
The above finding reveals the routine of these students. He shares by suggesting that if student is active in class then except that time of class, he/she can give remaining time to extra-curricular activities. However, he also shares other side that if student is dull in class and gives out-of-the-class time to extracurricular activities then academic life of that student will get disturbed. He suggests that remain active in class, take active participation in classroom activities, take important notes, and then review that before the examinations are some of the key factors of getting success in the examinations, He advises that after giving such serious time to studies, a student can give remaining time to extra-curricular activities.

On the other hand, another student of Business Department, studying in BBA semester 8 shared in the interview about his experiences self-regulated learning by getting rid from social media and give time to studies. He added:

If there is important work when there is deadline, so I turn of the internet of my mobile and laptop so after that there is no notification then after doing my work, I turn that on. Because when internet is on then notifications comes in mobile again and again then attraction increases, and we get attentive to that side.

It is an impressive strategy of disciplining the study time as this student has adopted the practice of turning off the internet of his cellphone and laptop. If any task is important and there is deadline then this student turns off the internet of his mobile and laptop, then after doing the work, he turns that on. Through this practice he keeps himself away from the obsession of social media and give his total attention towards his studies.

While discussing about the hindering factors, and strategies to address the hindering factors, one of the students of the BBA semester 8 students, who was interviewed for this study shared some more self-regulated suggestions for students. He explained:

I will give only one suggestion that maintain your diary and make daily to do list. Today I get this assignment tomorrow I have to do this thing, and this thing and until your to do list is not completed you should not sleep. If you schedule your activities your life becomes a lot easier. Make a to do list that tomorrow I have to do this thing this thing and do it on daily basis rather than keeping the things on procrastination [...] do not delay things as much you will delay it will become a problem for you.

The above findings display a systematic timetable for student to schedule their routine by this student. He simply suggests other students to maintain their diary and write about the activities which they have to do in a day and try to complete all the written activities within that day. He further added that through this activity the life of students becomes easier as it will run through a systematic way without any hurriedness. Moreover, another student of BBA degree who is in semester 8 talks about suggestion for taking part in extra-curricular activities, she added:

From 1st to 5th semester don't go [in extra-curricular activities] then after that go for it. Do hard work and struggle continuously [...] Follow the books, teachers' given articles, main thing is to focus on teachers' lectures $[\ldots]$ Whatever teacher is saying write that. If you are not writing than at least you should record it than listen that at your home, it will be very helpful [...] Secondly use the internet if you are not following books then follow the internet.

Above findings show that according to this student, other students should participate in extra-curricular activities after 5th semester. This student suggests that till fourth semester students should not get part in extra-curricular activities, as it may disturb their learning. Moreover, hardworking is key to success as per this student because she suggests other students to do hard work until they get their goal. This student suggests some major things to follow in classroom including teachers' lectures, course books, notes from class and recordings. She suggests about writing and recording the lectures of teachers to review after the class, and to get success in studies. Moreover, this student also suggests using the internet sources for study purpose in order to get learn the different concepts of different courses. 
Table 1. Identified themes emerged from codes

\begin{tabular}{|c|c|c|}
\hline S.No & Themes & Codes \\
\hline 1 & Perspectives for Learning Facilitates to get 3+ GPA & $\begin{array}{l}\text { Sources of learning } \\
\text { Perspectives on grading policy } \\
\text { Practice for getting 3+ GPA } \\
\text { Learning } \\
\text { Study time in University } \\
\text { Resources used in University } \\
\text { Visit to teacher } \\
\text { Study time in holidays } \\
\text { Maintaining study routine } \\
\text { Perspectives of 3+ GPA } \\
\text { Giving importance to 3+ GPA } \\
\text { Importance of 3+ GPA in fields } \\
\text { Importance of 3+ GPA in Institutes } \\
\text { Role of GPA in academics } \\
\text { Maintaining 3+ GPA } \\
\text { Maintaining study routine } \\
\text { Views about extracurricular activities } \\
\text { Participation in extracurricular activities } \\
\text { Views about social learning } \\
\text { Hard work }\end{array}$ \\
\hline 2 & Key facilitating factors that influence to achieve $3+$ GPA & $\begin{array}{l}\text { Rapport building } \\
\text { Essential practice for 3+ GPA } \\
\text { Suggestion for students } \\
\text { Benefits of 3+ GPA } \\
\text { Attention seekers subjects } \\
\text { Sources except books } \\
\text { Assignment preparation } \\
\text { Group Vs Individual work } \\
\text { Learning environment } \\
\text { Preferred learning environment } \\
\text { Prefer Teaching Method } \\
\text { Most liked activity } \\
\text { Learning through extracurricular activities } \\
\text { Help of social learning } \\
\text { Set a goal }\end{array}$ \\
\hline 3 & Key hindering factors that affect achieving 3+ GPA & $\begin{array}{l}\text { Reason of low GPA } \\
\text { Least liked activity } \\
\text { Hindrance through extracurricular activities } \\
\text { Harmful } \\
\text { Managing time } \\
\text { Hindering factors } \\
\text { Addressing hindering factors } \\
\text { Suggestions }\end{array}$ \\
\hline
\end{tabular}

\section{Discussion and Conclusions}

The purpose of this qualitative case study was to get insights about the learning perspectives of students who obtain 3+ GPA at the Business Department of a Public Sector University in Sindh, Pakistan.

Data was collected through a series of semi structured interviews from research participants of this study. The major areas which were asked in interview guides included questions regarding, learning perspectives which includes different perspectives and thoughts about learning from the side of students, perspectives about grading policy considering the basic standards of grading policy, learning practices of students including the various sources which students seek and use in their learning, facilitating factors which contribute further in learning, hindering factors which limit the learning practices and suggestions which guide further about the ways and new policies of learning. Throughout the interviews, several probing questions were asked to understand the perspectives of research participants' deeply. Interviews were conducted in two phases i.e. one-to-one and follow-up interviews.

Current study shows that learning is about applying knowledge. Findings of this study reveals that students perceive learning as practicality approach. Students perceive that learning is whatever they perform in perspective of physical condition and their learning occurs when they are provided with any situation in real context. In contrast to this, Duarte explains that learning is perceived as a combination of memorization and understanding, especially in Asian countries. It shows that the findings of this study oppose the findings of Duarte as 
current study explicitly shows that learning is perceived as application approach.

Grade point average (GPA) plays important role in university life of students. It is used to rank students' performance, which has become important measure in universities [16]. Moreover, obtaining 3+ GPA has given a lot of importance in business institutes across the world. Consistently, the finding of this study is revealing that the Public Sector University, where this study was conducted, gives emphasize on students to maintain 3+ GPA. It reveals that university and teachers give more focus on maintaining 3+ GPA because companies demand for those students who have $3+$ GPA. With rapid growth of industrialization, the demand for professional managers and trained executives is also increasing and business schools give more focus on the grades as companies' demand for such students who obtain good grades and maintain 3+ GPA [21]. Similarly, this study's findings reveal that the students of Business Department (who were interviewed for this study) maintained their GPA as well as they enhance their skills. Findings show that students in business department set their focus towards getting 3+ GPA. One of the students shares that she is aware about the demand of market and for that she has set her mind to get 3+ GPA and do hard work for getting the GPA.

The resources like library, computer labs, and laboratories and also other activities including classroom learning activities, seminars, academic programs and recreational activities have greater influence on students [17]. In consistent with Robbins et al., this study also shows that those students who obtained such good GPA are more likely to prefer University library, issue books, use multiple resources and also take active part in extra-curricular activity which helps them to learn more skills including communication skills, presentation skills, confidence and speaking skills. Similarly, another study conducted by Kuh, Cruce, Shoup, Kinzie and Gonyea, also reports that students' success in university is influenced by many factors including academic achievement, satisfaction, and engagement in educational focused activities, acquisition of knowledge, skill and competencies and accomplishment of educational objectives.

Wernersbach et al., share that students face number of challenges including adjustment of college life, financial struggle, stress level and lack of study strategies further, it shows that students who are unable to overcome such challenges are more likely to drop out from university. In addition to this, current study reveals some more factors which affect students' learning including family events (marriages, funerals), friend circle, social media and taking more part in extra-curricular activities which divert students' mind from learning. Wernersbach et al., added that for facilitating such challenges, university arrange seminars and workshops regarding study strategies and skill courses. However, it is interesting to note that the current study shows students' practices which they adopt to address such hindering factors. Findings of this study show that students maintain a systematic timetable to schedule their routine and complete the required task on the planned day. It also shows that for attending important events in family, students complete their task before the given deadline and for giving their total attention to studies, they turn off their internet and get rid from social media.

Students' learning perspectives are obtained through the way they guide their studies and approach their learning task [10]. Inclusively, the findings of this research study have revealed the different learning perspectives of those students who maintained their $3+$ GPA from $1^{\text {st }}$ to $8^{\text {th }}$ semester in BBA degree of the Business Department in a Public Sector University. The major focus was remained on sharing the learning perspectives of students, learning practices to maintain 3+ GPA, facilitating factors for getting 3+ GPA and key hindering factors that affect 3+ GPA. The findings also highlight the reasons behind getting low GPA in academics. Finding also show the harmful factors which hinder students' learning and also suggestions to address those factors. The findings identify that students give importance to their routine in the start of the semester, but as semester passes, they give less focus to their routine. It reveals that in the start of the semester, students are conscious about their GPA as soon as the semester passes, and their GPA is maintained, then they also divert their focus and take excessive part into extra-curricular activities and give less time to their studies. Nevertheless, findings portray the importance of extra-curricular activities, it shows that through these extra-curricular activities students enhance their different skills like teamwork, management and presentation skills. Moreover, findings also display that extra-curricular activities also hinders students' learning if students shift their focus and give more time to extra-curricular activities then academic studies. Findings also show some important suggestion for students to adopt for participating in extra-curricular activities by maintaining a balance time allocation to their academic studies and engagement in the extra-curricular activities.

The importance of this study can be defined at four diverse levels. First of all, this study has explored the perspectives of students who obtain 3+ GPA. Thus, it provides different viewpoints of students about the learning and grading policy of their university. Secondly, it provides the vast variety of practices followed by students who maintain their 3+ GPA. It gives an opportunity to other students to reflect on their practices and adopt the shared practices for maintaining their 3+ GPA in university. Thirdly, it also gives the representation of facilitating and hindering factors to get 3+ GPA that occurs to students in university. Fourthly, this study presents suggestions for students to adopt different strategies that will help them to get freed from the different factors that hinder their studies and affect their GPA.

I aspire that the expected outcomes of this study will 
open a window to facilitate those students who could not get a good GPA during their studies in a university setting. As this study has explored the different learning perspectives of students who obtain 3+ GPA, so it will provide an opportunity for low achieving students to get higher GPA by applying the results of this study. Findings will also offer an area of consideration to educational institutes and universities to discover new ways and incorporate different perspectives of learning in their system. Moreover, these findings will also help teachers of university. It will help them to incorporate new ways of learning in their classroom and employ different ways of teaching methods. Lastly, findings will provide opportunity for policy makers, it will help them to update their policies which facilitate students' learning.

Keeping in mind the resources and time limitation, this study was conducted in the Business Department of a Public Sector University with four participants, having four one-to-one and two follow-up interviews. Nevertheless, this study will help to identify the improvement areas for students who achieve low grades in their studies. The future research can be conducted in the same department of Public Sector University with those participants who achieve less than 3 GPA. This will help to compare and contrast the practices of low and high achievers and thus will be more helpful to identify the difference between these practices. It will also facilitate the parents, teachers and educational institutes to make positive changes in their educational system and offer different opportunities of leaning to their students.

\section{REFERENCES}

[1] Collins dictionary online available from, https://www.collinsdictionary.com/dictionary/english/pers pective

[2] P. Ramburuth, R. Mladenovic. (2014), Exploring the relationship between students' orientations to learning, the structure of students' learning outcomes and subsequent academic performance, Accounting Education, Vol. 13, No. 4, 507-527, 2014.

[3] S. Lindblom-Ylanne, A. Parpala, L. Postareff, what constitutes the surface approach to learning in the light of new empirical evidence?, Studies in Higher Education, Vol. 44, No. 12, 2183-2195, 2019.

[4] BA. Trammell, RS. Aldrich. Undergraduate Students' Perspectives of Essential Instructor Qualities, Journal of the Scholarship of Teaching and Learning, Vol. 16, No. 1, 15-30, 2016.

[5] A. Tapola, M. Niemivirta. The role of achievement goal orientations in students' perceptions of and preferences for classroom environment, British Journal of Educational Psychology, Vol. 78, No. 2, 291-312, 2008.

[6] E. Alfan, N. Othman. Undergraduate students' performance: the case of University of Malaya, Quality assurance in education, 2005.

[7] AA. Shah, HM. Irshadullah, H. M. The factors affecting students' academic performance at Abdul Wali Khan University Mardan, Pakistan, Research Journal of Education, 59-67, 2018.

[8] K. Yilmaz. Constructivism: Its theoretical underpinnings, variations, and implications for classroom instruction, Educational horizons, Vol. 86, No. 3, 161-172, 2008.

[9] S. Shim, A. Ryan. Changes in self-efficacy, challenge avoidance, and intrinsic value in response to grades: The role of achievement goals, The Journal of Experimental Education, Vol. 73, No. 4, 333-349, 2005.

[10] F. Han, RA. Ellis. Identifying consistent patterns of quality learning discussions in blended learning, The Internet and Higher Education, Vol. 40, pp. 12-19, 2019.

[11] RG. Schwab, I. Kral. Youth literacy and learning spaces, Learning Spaces: Youth, Literacy and New Media in Remote Indigenous Australia, ANU Press, 93-102, 2012.

[12] YC. Kuo, BR. Belland, YT. Kuo. Learning through Blogging: Students' Perspectives in Collaborative Blog-Enhanced Learning Communities, Journal of Educational Technology \& Society, Vol. 20, No. 2, 37-50, 2017.

[13] M. Ahmed. 6 Lifelong Learning in a Learning Society: Are Community Learning Centres the Vehicle?, Brill Nijhoff, In Education, learning, training, International development policy, Vol. 5, pp. 102-125, 2014.

[14] AM. Duarte. Conceptions of learning and approaches to learning in Portuguese students, Higher Education Vol. 54, No. 6, 781-794, 2007.

[15] BJ. Fishman. Designing usable interventions: bringing student perspectives to the Table, Instructional Science, Vol. 42 No. 1, 115-121, 2014.

[16] DM. Lang. Class rank, GPA, and valedictorians: How high schools rank students, American Secondary Education, 36-48, 2007.

[17] S. Robbins, J. Allen, A. Casillas, A. Akamigbo, M. Saltonstall, R. Campbell, P. Gore. Associations of Resource and Service Utilization, Risk Level, and College Outcomes, Research in Higher Education, Vol. 50, No. 1, 101-118, 2009.

[18] R. Stupnisky, R. Renaud, L. Daniels, T. Haynes, R. Perry. The Interrelation of First- Year College Students' Critical Thinking Disposition, Perceived Academic Control, and Academic Achievement, Research in Higher Education, Vol. 49, No. 6, 513-530, 2008.

[19] Bowers, J. Alex.Grades and graduation: A longitudinal risk perspective to identify student dropouts, The Journal of Educational Research Vol. 103, No. 3, 191-207, 2010.

[20] B. Wernersbach, S. Crowley, S. Bates, C. Rosenthal. Study Skills Course Impact on Academic Self-Efficacy, Journal of Developmental Education, Vol. 37, No. 3, 14-33, 2014.

[21] SN. Waseem, T. Zarif. Factors affecting students' choice for degree in business Administration, Journal of management and social sciences, Vol. 8, No. 1, 40-47, 2012. 
[22] R. Ullah, JT. Richardson, M. Hafeez, M. Approaches to studying and perceptions of the academic environment among university students in Pakistan, Compare, Vol. 41, No. 1, 113-127, 2011.

[23] P. Hoodbhoy. Pakistan's higher education system-What went wrong and how to fix it, The Pakistan Development Review, Vol. 48, No. 4, 581-594, 2009.

[24] A. Kuper, S. Reeves, W. Levinson. Qualitative Research: An Introduction to Reading and Appraising Qualitative Research, British Medical Journal, Vol. 337, No. 7666, 404-407, 2008.

[25] LT. Choy. The strengths and weaknesses of research methodology: Comparison and complimentary between qualitative and quantitative approaches, IOSR Journal of Humanities and Social Science, Vol.19, No. 4, 99-104, 2014.

[26] LR. Johnson. Community-based qualitative research: Approaches for education and the social sciences. Sage Publications, 2016.

[27] RC. Bogdan, SK. Biklen. Qualitative research for education: An introduction to theories and methods. 2007. Perason Education Group, New York. 2007.

[28] JW. Creswell. Educational research: Planning, conducting, and evaluating quantitative and qualitative research (5th ed.), Pearson education, Boston MA, 2015.

[29] MB. Miles, AM. Huberman, J. Saldana, J. Qualitative data analysis, Sage Publication, 2013

[30] JA. Maxwell, Qualitative Research Design: An Interactive Approach (3rd ed.), SAGE Publications, Los Angeles CA, 2013.

[31] JW. Creswell, DL. Miller, Determining validity in qualitative inquiry. Theory into practice, Vol 39 No. 3, pp. 124-130, 2000. 3

[32] GD. Kuh, TM. Cruce, R. Shoup, J. Kinzie, RM. Gonyea, Unmasking the effects of student engagement on first-year college grades and persistence", The journal of higher education, Vol. 79 No. 5, pp. 540-563, 2008. 